\title{
Retinoid acid receptors in human colorectal cancer: An unexpected link with patient outcome
}

\author{
AURÉLIE PERRAUD ${ }^{1,2,3}$, MICHELLE NOUAILLE ${ }^{3}$, HUSSEIN AKIL $^{1,2}$, DANIEL PETIT $^{5}$, \\ FRANÇOIS LABROUSSE ${ }^{4}$, MARIE-ODILE JAUBERTEAU ${ }^{1,2}$ and MURIEL MATHONNET ${ }^{1,2,3}$ \\ ${ }^{1}$ EA 3842, Homéostasie Cellulaire et Pathologies, Faculté de Médecine et de Pharmacie, and \\ ${ }^{2}$ Institut Génomique Environnement Immunité Santé Thérapeutiques (IFR 145 GEIST), Université de Limoges, \\ 87025 Limoges Cedex; ${ }^{3}$ Service de Chirurgie Digestive Endocrinienne et Générale, and ${ }^{4}$ Laboratoire d'Anatomopathologie, \\ CHU de Limoges, 87042 Limoges Cedex 1; ${ }^{5}$ UMR 1061 INRA/Université de Limoges, 87060 Limoges Cedex, France
}

Received January 31, 2011; Accepted March 9, 2011

DOI: 10.3892/etm.2011.242

\begin{abstract}
The status of the three retinoic acid receptors (RARs) $\alpha, \beta$ and $\gamma$ in human colorectal cancer (CRC) has not as yet been examined. RARs are in part responsible for the actions of the retinoids (vitamin $\mathrm{A}$ and its derivatives), which are essential for human health and survival due to their extensive involvement in numerous cellular processes, in particular in epithelial morphology. The present study examined the expression of the three RARs in CRC using immunohistochemical analysis of paraffin-embedded tissue sections. RAR expression in tumor (T) and adjacent non-tumor (NT) specimens from stage I $(n=6)$, stage II $(n=34)$, stage III $(n=26)$ and stage IV $(n=14)$ CRC patients was compared with that in normal mucous membranes $(n=10)$ from control individuals. The findings were correlated with tumor grade, treatment response (progression during treatment, remission, chemoresistance) and survival as clinicopathological parameters. RAR $\alpha$ and $\gamma$ expression was decreased with CRC stage in the $\mathrm{T}$ tissues $(\mathrm{P}=0.016$ and $\mathrm{P}=0.052$, respectively), suggesting that they may be used as predictive markers. RAR $\beta$ expression in the NT tissues was associated with a more favorable prognosis $(\mathrm{P}=0.04)$. These results provide important information on the tumor microenvironment (the area adjacent to tumor cells).
\end{abstract}

\section{Introduction}

With its first description in 1925, Wolbach and Howe implicated vitamin A and its derivatives (retinoids) in epithelial development and tumorigenesis (1). The activity of vitamin A, apart from that involved in vision, is mediated by retinoids.

Correspondence to: Dr Aurélie Perraud, Université de Limoges, EA 3842, Homéostasie Cellulaire et Pathologies, Faculté de Médecine et de Pharmacie, 2 rue du Dr Marcland, 87025 Limoges Cedex, France

E-mail: aurelie.perraud@unilim.fr

Key words: colorectal cancer, biomarkers, response to treatment
Many years later, De Luca further implicated the retinoids in differentiation and embryogenesis (2) by showing their effects on limb development, epithelial integrity and tumorigenesis. Since they are involved in numerous life processes (embryogenesis, cell growth, cell differentiation and cell death), retinoids are essential for life. One of their most important actions is their antitumor activity, whereby they inhibit tumor growth and promote apoptosis $(3,4)$. This has led to their therapeutic application against cancer, for example in the treatment of acute promyelocytic leukemia $(5,6)$.

Retinoids cross the cell membrane through hydrophobic interactions and/or endocytosis in order to bind to their specific receptors: the retinoic acid receptors (RARs) (7) and rexinoid receptors (RXRs) (8-10). When retinoids are present in cells, they bind the RAR/RXR heterodimer, which acts as a transcription factor. The retinoid-receptor complex binds to the retinoic acid response element sequence, located near the promoter of target genes, to induce or inhibit transcription (3).

The RAR family comprises three members: $\alpha, \beta$ and $\gamma$. RAR $\beta$ expression is frequently reduced in tumor cells, probably due to the hypermethylation of its promoter $(11,12)$, and in association with tumor progression in different organs or with pathologies in head and neck tissues (13), basal skin cells (14), breast (15), lung (16), esophagus (17), prostate (18), thyroid (19), larynx (20), endometrium (12) and oral tissues (21). All of these studies have concluded that RAR $\beta$ should be considered a tumor suppressor (22). However, studies on RAR $\alpha$ and $\gamma$ expression have reported conflicting results, depending on the pathology and the technique used.

To the best of our knowledge, the expression of the RARs has not been reported in patients with colorectal cancer (CRC). In France, CRC is the second most common cancer in men and the third most common in women (23). This pathology is classified as the second leading cause of cancer-related death in industrialized countries (National Cancer Institute data), and the 5-year survival rate is very low. CRC development is characterized by four tumor stages, defined by the International Pathology Tumor Node Metastasis (pTNM) classification system (24), which is used as the diagnostic system upon which patient treatment is based. However, few proteins predictive of response have been identified. 
RARs are implicated in homeostasis and, in particular, in epithelial morphology, which led us to hypothesize that the expression of these receptors is implicated in CRC development. Since few predictive proteins are available for CRC, the aim of this study was to examine the cellular distribution of the three RARs by immunohistochemical analysis of normal and pathological human colon tissues from different tumor stages. Their expression was compared to the cell proliferation rate, which is known to be associated with tumor growth, and was detected by immunostaining for Ki-67. The results revealed the importance of RAR signaling in the progression of CRC. Correlations with tumor grade, therapeutic response and survival were established.

\section{Materials and methods}

Patients and tissue samples. All cases of histologically confirmed CRC were included, regardless of whether the patients had received chemotherapy. Based on the Helsinki protocol, the exclusion criteria included juvenile patients, pregnant or breast-feeding women, rectal or colonic lesions that were not histologically confirmed to be CRCs, patients in whom follow-up was impossible and insufficient or unexploitable tissue due to inadequate preservation.

Archived formalin-fixed paraffin-embedded blocks of colon tissues were obtained from the Pathology Department of the Limoges Teaching Hospital. The specimens were from consecutive patients who underwent elective resection for CRC between January 2006 and December 2007. Eighty patients (37 women and 43 men) with a mean age of 71 years (range 41-93) were included prospectively. The first follow-up evaluation was made on October 31, 2008, with a median follow-up time of 24 months (range 11-32). The second followup evaluation was made on December 15,2010, with a median follow-up time of 46 months (range 25-66). The tumors were graded according to the pTNM international classification (24). Forty patients had local disease (stage I, T1/2-N0, n=6; stage II, T3/4-N0, n=34), 26 had regional lymph-node involvement (stage III, any T-N1/2) and 14 had advanced disease (stage IV, any $\mathrm{T}$, any $\mathrm{N}$, presence of metastasis). Histological slides of the primary tumor were reviewed to identify the normal-appearing areas adjacent to the tumor sites and the tumor areas, excluding the central tumor zone, which was usually necrotic. The tissue blocks were sectioned $(4-\mu \mathrm{m}$ thick) and stained with H\&E saffran (HES) for pathological diagnosis, TNM grading and immunostaining.

Histologically normal colon tissues from 10 patients who had been treated for benign pathologies, such as idiopathic chronic constipation $(n=7)$ or diverticulosis $(n=3)$, constituted the control group and were used to determine the constitutional expression.

Clinical and pathological parameters. Clinical, paraclinical (biological and imaging) and histological parameters were collected by Michelle Nouaille and technicians at the Pathology Department, Limoges Teaching Hospital, at the time of patient admission. The patients all underwent a uniform postoperative follow-up by the same team: they were examined within 1 month of resection, then every 3-4 months for the first year, every 6 months for the next
3 years and then at gradually increasing intervals. A clinical examination and quantification of serum carcinoembryonic antigen (CEA) were performed at each visit. Computed tomographic (CT) scans were performed every 6-12 months. A full colonoscopy was performed 1 year after surgery, then once every 3-5 years. Positron emission tomographic (PET) scans were selectively performed when abnormalities or axial imaging raised the possibility of recurrence. Local recurrence was defined as the first clinical, radiological and/ or pathological evidence of a tumor of the same histological type within the colon. Distant recurrence was defined as clinical, radiological and/or pathological evidence of systemic disease at sites including, but not limited to, the liver, lungs, peritoneum and para-aortic region. Recurrence-free survival and disease-specific survival were analyzed. 'Evolution' was defined as disease progression without adjuvant therapy, 'chemoresistance' as disease progression during or after adjuvant therapy, and 'remission' as the absence of clinical signs of disease progression.

Antibodies. The antibodies used were rabbit polyclonal antibodies raised against a peptide mapping to the C-terminus of human RAR $\alpha$ (sc-551; Santa Cruz Biotechnology, Le-Perrayen-Yvelines, France), human RAR $\beta$ (sc-552) or human RAR $\gamma$ (sc-550). The commercially available antibody for Ki-67 (M7240; DakoCytomation SA, Trappes, France), which recognizes a $395-\mathrm{kDa}$ nuclear protein expressed during cell-cycle phases (G1, S, G2 and M) (25) was used. For the isotypic controls, we used immunoglobulin G (IgG) (rabbit, I8140 and mouse, I8765; Sigma, St. Quentin Fallavier, France).

Control of antibody specificity. Total proteins from the WiDr cell line (American Type Culture Collection) were extracted using a lysis buffer following the manufacturer's recommendations (Cell Signaling Technology, Ozyme, St. Quentin Yvelines, France) in order to perform Western blotting. The results showed that RAR proteins stained at the expected molecular weights, without non-specific binding, as determined with isotypic controls for the three anti-RAR antibodies (data not shown).

Immunohistochemistry. Ki-67, $\mathrm{RAR} \alpha$ and $\operatorname{RAR} \gamma$ were immuno-histochemically detected in paraffin-embedded tissues using the BenchMark technology (Ventana Medical Systems, Illkirch, France). The pathway RAR $\alpha$ and RAR $\gamma$ staining module was used according to the $\mathrm{Ki}-67$ protocol according to the manufacturer's instructions. The processing of the bar-code-labeled slides was fully automated and included the following steps: baking the slides, solvent-free deparaffinization and antigen retrieval in $\mathrm{CC} 1$ cell-conditioning buffer $\left(30 \mathrm{~min}\right.$ at $\left.95^{\circ} \mathrm{C}\right)$. The samples were incubated with the primary antibody previously diluted in diluent solution (1:50 for $\mathrm{Ki}-67,1: 100$ for $\operatorname{RAR} \alpha$ and 1:150 for $\operatorname{RAR} \gamma$ ) for $32 \mathrm{~min}$ at $37^{\circ} \mathrm{C}$. Horseradish peroxidase (26)-coupled secondary antibody was added $\left(8 \mathrm{~min}\right.$ at $\left.37^{\circ} \mathrm{C}\right)$, thenthe proteins were detected with the chromogenic substrate diaminobenzidine $(\mathrm{DAB})\left(8 \mathrm{~min}\right.$ at $\left.37^{\circ} \mathrm{C}\right)$. The tissue sections were also counterstained with hematoxylin $\left(12 \mathrm{~min}\right.$ at $\left.37^{\circ} \mathrm{C}\right)$ and a bluing reagent $\left(4 \mathrm{~min}\right.$ at $\left.37^{\circ} \mathrm{C}\right)$ to increase the contrast. The slides were mounted with a non-aqueous mounting medium. 
For RAR $\beta$ immunohistochemistry, paraffin sections were deparaffinized in toluene and alcohol, and rehydrated with phosphate-buffered saline (PBS). Before staining, the sections were subjected to steam heat antigen retrieval in citrate buffer (200 $\mu \mathrm{M}$ citric acid, $9.8 \mathrm{mM}$ sodium citrate, $\mathrm{pH}$ 7.0) for $5 \mathrm{~min}$. This step was repeated four times in a microwave oven $(750 \mathrm{~W})$. After washing in PBS, the slides were incubated for 10 min with $5 \% \mathrm{H}_{2} \mathrm{O}_{2}$ in methanol to inhibit endogenous peroxidases. Non-specific sites were blocked with PBS-3\% bovine serum albumin (BSA) for $30 \mathrm{~min}$. The sections were then incubated with the primary antibody (1:500) in PBS-3\% BSA for $1 \mathrm{~h}$ at room temperature. After washing, the epitopes were labeled with the anti-rabbit HRP Envision ${ }^{\mathrm{TM}}$ plus system and visualized with liquid DAB (Dako SA). The sections were couterstained and examined with a Leica microscope, and the images were captured with a Zeiss camera.

To test the specificity of the signals, negative control experiments were performed either by omitting the primary antibody, by substituting the primary antibody with nonimmune serum, or by omitting both the primary and secondary antibodies. No staining was observed in any of the negative controls (data not shown).

Quantification of immunostaining. Photomicrographs of each slide were captured with a Zeiss microscope with a magnification of x200. The most homogeneously stained tumor (T) and non-tumor (NT) areas on each slide were selected for quantification. Immunoreactivity was scored by a staining index based on the percentage of positive cells, by a semi-quantitative estimate, as follows: $(-; 0)$, tissue with negative staining; $(+; 1)$, tissue with staining in $25-49 \%$ of cells; $(++; 2)$, tissue with staining in $50-74 \%$ of cells; $(+++; 3)$, tissue with staining in $\geq 75 \%$ of cells. 'Overexpression' was defined as a staining index of $\geq 75 \%$. The results were expressed as the mean of three independent quantifications made by different individuals.

Statistical analysis. The overall variations in the staining percentages for the RARs and Ki-67 and their relationships to tumor grade were evaluated by analysis of variance (ANOVA) using SYSTAT 12.0 (SPSS, 2007). Tukey's post hoc test was used to assess the significance of the differences between the stages, and P-values $<0.05$ were considered significant. Correlations between the parameters were visualized by cluster analysis using Spearman's @ as the measure of similarity, using PAST 1.83 (27). Survival curves were constructed using the free-access software of the Dartmouth-Hitchcock Norris Cotton Cancer Center (http://biostat.hitchcock.org/ BSR/Analytics/CompareTwoSurvivalDistributions.asp).

\section{Results}

Baseline characteristics and overall survival. The overall 2-year survival rate was $70 \%$, probably due to the age of the patients and the high proportion of advanced-stage cases. At the time of analysis, patient survival was $100 \%$ for stage I, $75 \%$ for stage II, $65 \%$ for stage III and $47 \%$ for stage IV. Nine patients (8 with stage II and 1 with stage III) died of causes not related to CRC (cardiac or neurological etiologies). Adjuvant chemotherapy was administered for stages III and IV. Twenty patients received no adjuvant therapy (16 stage III and 4 stage IV) due to postoperative
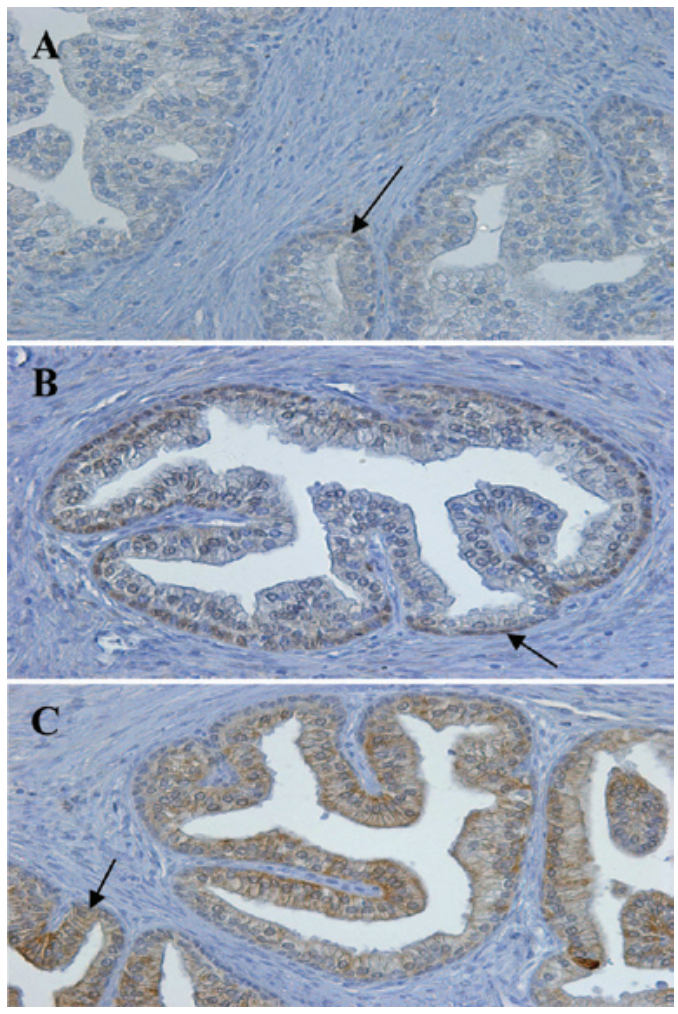

Figure 1. Immunohistochemical localization of $\operatorname{RAR} \alpha, \beta$ and $\gamma$ in normal human prostate. Immunohistochemical staining was carried out on paraffinembedded sections (4- $\mu \mathrm{m}$ thick), using primary antibodies as follows: (A) anti-RAR $\alpha$ (1:100 dilution), (B) anti-RAR $\beta$ (1:100 dilution) and (C) antiRAR $\gamma$ (1:150 dilution). The Envision system was used as the secondary antibody. Original magnification, x200.

death $(n=3)$, age $>85$ years $(n=14)$ and/or patient refusal $(n=3)$. Cancer progression occurred in $11 / 20$ patients and cancer recurrence in 9/11 patients during adjuvant chemotherapy.

Two years later, at the second evaluation, 77 patients had continued with the follow-up ( 3 had been lost). At this time, the overall 4-year survival rate was $49 \%$; patient survival was $100 \%$ for stage I, $48 \%$ for stage II, $54 \%$ for stage III and $23 \%$ for stage IV. Apart from 5 stage II patients who died due to unrelated causes, 10 patients (5 in stage II, 1 in stage III and 4 in stage IV) succumbed to CRC during the interval between the first and the second evaluations.

Control of RAR expression in normal prostate. The use of antibodies against RARs for immunohistochemistry of chemically fixed tissues was previously tested in prostate tissue (18). When different antibody dilutions (1:50 to 1:500) were tested, the results obtained in normal prostate tissue were reproducible, with localization patterns similar to those described by Richter et al (18). As shown in Fig. 1 (arrows); for RAR $\alpha$, homogeneous staining in the cytoplasm with little nuclear staining was noted; for $\operatorname{RAR} \beta$, the presence of staining in the basal nuclei was noted; for RAR $\gamma$, homogeneous staining in the epithelial cytoplasm with little nuclear staining was observed. Since these results confirmed the specificity of the anti-RAR antibodies, they were used on the CRC tissues.

Ki-67 and RAR expression in different stages of $C R C$. The constitutional expression of the proteins was first evaluated 

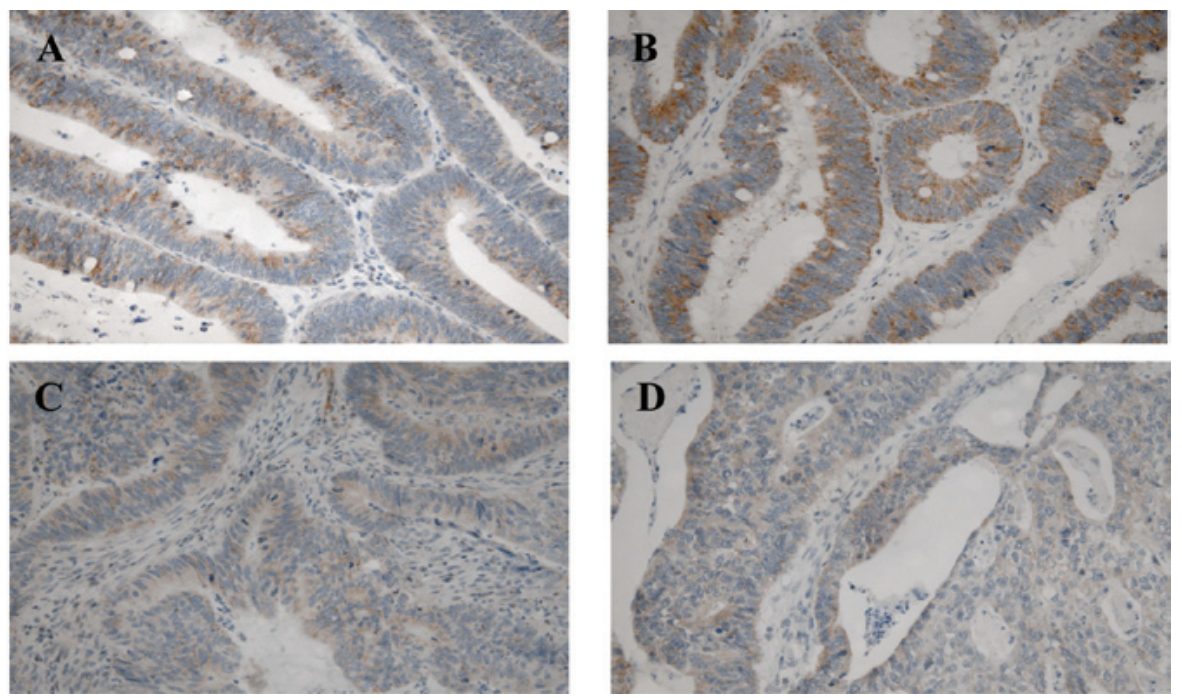

Figure 2. Immunohistochemical localization of RAR $\alpha$ in the tumor areas of samples from patients with different stages of CRC. (A) Stage I, (B) stage II, (C) stage III and (D) stage IV. Immunohistochemical staining was carried out on paraffin-embedded sections (4- $\mu$ m thick) using a primary antibody against $\mathrm{RAR} \alpha(1: 100)$ and the Envision system as the secondary antibody. Original magnification, $\mathrm{x} 200$.

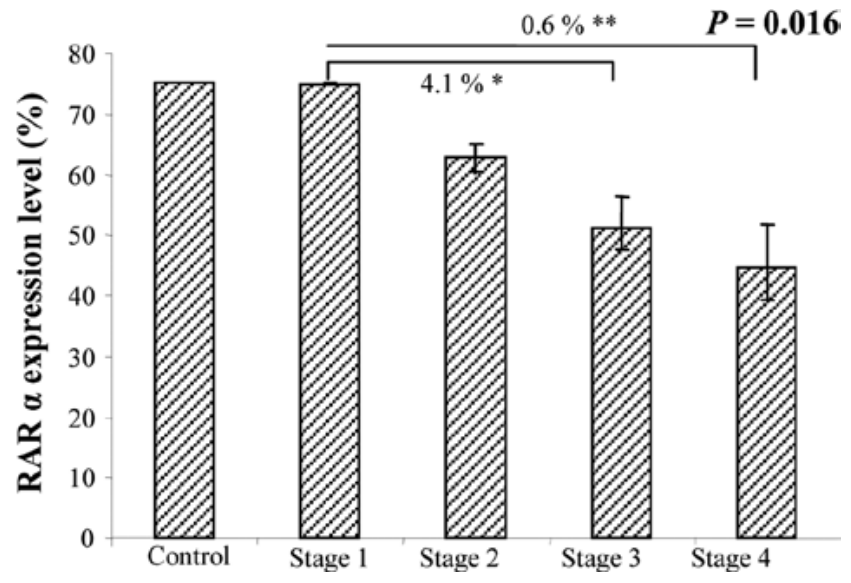

Figure 3. ANOVA analysis of RAR $\alpha$ expression in the tumor areas in different CRC stages. by immunohistochemistry in the normal control group, then examined in the adjacent NT tissue of each patient, for use as an internal control. The Ki-67 and RAR staining profiles in the NT tissues were identical to those observed in the control group. Finally, the expression of the RARs was examined in the $\mathrm{T}$ and $\mathrm{NT}$ areas in the specimens from patients with different stages of CRC.

Random Ki-67 staining was detected in the nuclei of all the cells, located both inside and outside the $\mathrm{T}$ fields, with some differences in the percentages of labeled cells among patients (data not shown). However, ANOVA between the groups of different stages revealed no statistically significant differences $(\mathrm{P}>0.05)$.

RAR $\alpha$ staining was uniformly detected in the cytoplasm of the epithelial cells in the NT and T tissues (Fig. 2). Of the 80 patients analyzed, all expressed this receptor in the NT

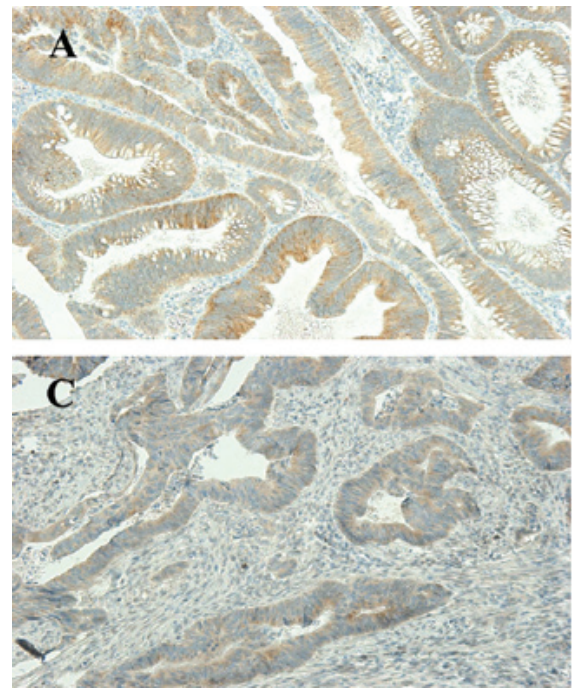

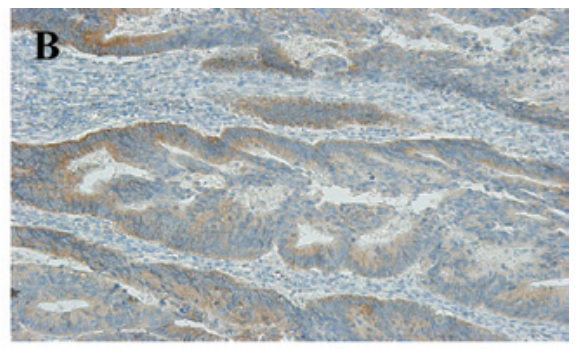

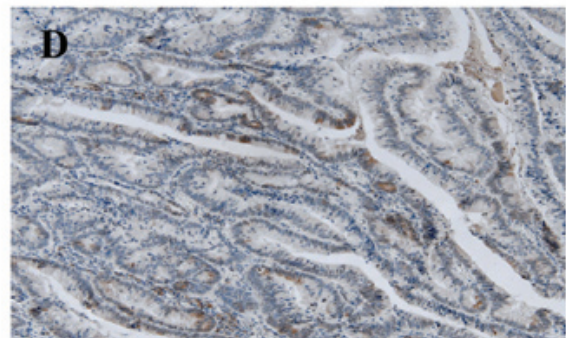

Figure 4. Immunohistochemical localization of RAR $\gamma$ in the tumor areas of samples from patients with different stages of CRC. (A) Stage I, (B) stage II, (C) stage III and (D) stage IV. Immunohistochemical staining was carried out on paraffin-embedded sections (4- $\mu \mathrm{m}$ thick) using a primary antibody against RAR $\alpha(1: 150)$ and the Envision system as the secondary antibody. Original magnification, x200. 


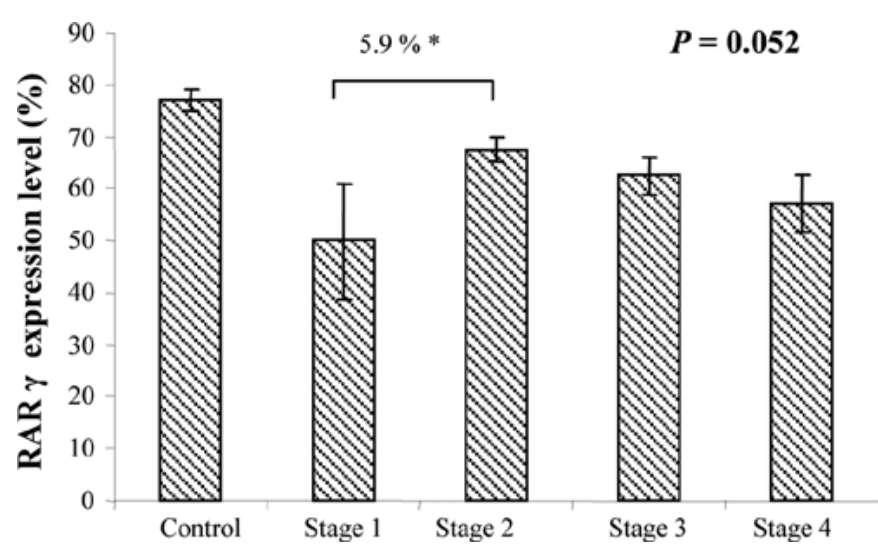

Figure 5. ANOVA of RAR $\gamma$ expression in tumor areas of samples from patients with different stages of CRC.
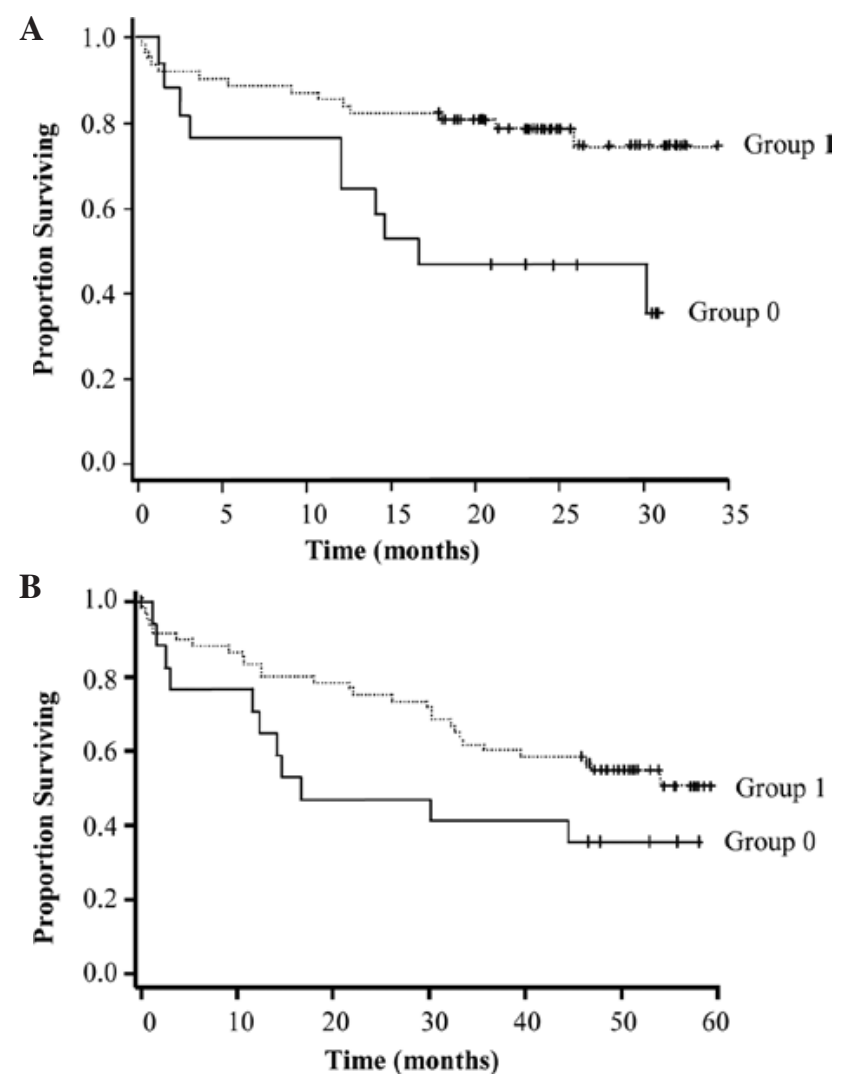

Figure 6. Kaplan-Meier estimation of survival probability of CRC patients based on RAR $\alpha$ expression in the tumor tissues. (A) Evaluation carried out at the first follow-up. Group 0 , patients in which $0-25 \%$ of cells expressed RAR $\alpha$; group 1, patients in which $75-50 \%$ of cells expressed RAR $\alpha$. Estimated relative risk $(\mathrm{RR})=0.327$; standard error $(\mathrm{SE})=0.136 ; \mathrm{P}=0.0072$. (B) Evaluation carried out at the second follow-up. Group 0, patients in which $0-25 \%$ of cells expressed RAR $\alpha$; group 1, patients in which $75-50 \%$ of cells expressed $\mathrm{RAR} \alpha$. $\mathrm{RR}=0.558 ; \mathrm{SE}=0.199 ; \mathrm{P}=0.1$.

tissues (50-75\% of cells), as did in the control group (data not shown). In the T tissues, only $6(7.5 \%)$ (stage II, $\mathrm{n}=1$; stage III, $\mathrm{n}=3$ and stage $\mathrm{IV}, \mathrm{n}=2)$ showed no expression, $11(13.75 \%)$ showed weak expression, 20 (25\%) showed moderate expression and most $(n=43 ; 53.75 \%)$ showed strong RAR $\alpha$ expression. At the inital evaluation, a statistically significant difference between stages was detected with ANOVA ( $\mathrm{P}=0.016)$ (Fig. 3). Indeed, RAR $\alpha$ expression in the $\mathrm{T}$ tissues was directly corre-

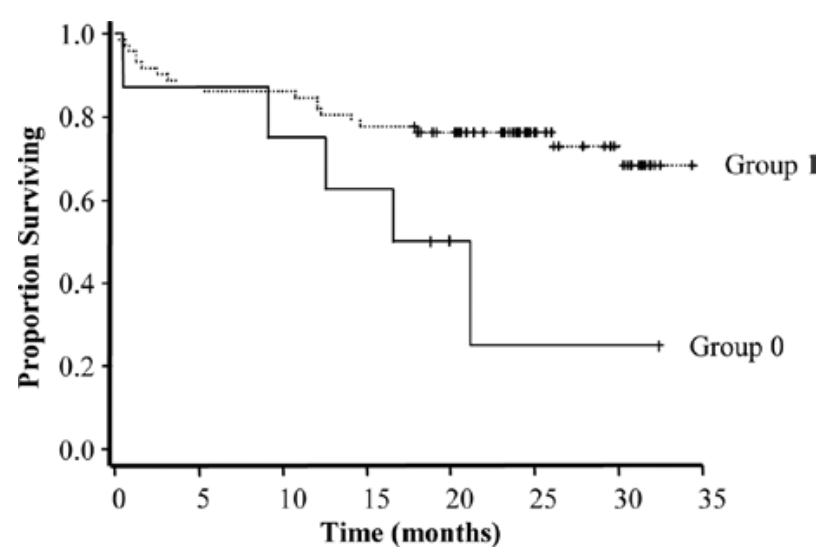

Figure 7. Kaplan-Meier estimation of survival probability of CRC patients based on RAR $\beta$ expression in NT tissue. Group 0 , patients in which $0-50 \%$ of cells expressed RAR $\beta$; group 1, patients in which $75 \%$ of cells expressed RAR $\beta$. The estimated relative risk is 0.355 ; the standard error is 0.179 and the $\mathrm{P}$-value is 0.04 .

lated with tumor stage, as it was predominantly expressed in the early rather than the late stages of CRC, when its expression decreased. Reinforcing this result, this tendency was maintained at the second evaluation $(\mathrm{P}=0.0018)$

RAR $\beta$ staining was restricted to the mucous membrane and was uniform in the cytoplasm of epithelial cells in the NT and $\mathrm{T}$ tissues. In the NT tissues, RAR $\beta$ was expressed as a mean of $71 \%$, comparable to that observed in the normal control group $(72.5 \%)$. In the $\mathrm{T}$ tissues, 15 patients $(18.75 \%$ ) (stage II, $\mathrm{n}=7$; stage III, $\mathrm{n}=4$; and stage IV, $\mathrm{n}=4)$ showed no expression, $4(5 \%)$ showed weak expression, $6(7.5 \%)$ showed moderate expression and most $(55 ; 68.75 \%)$ showed strong RAR $\beta$ expression. No statistically significant differences were observed between the CRC stages as analyzed by ANOVA $(\mathrm{P}>0.4)$.

RAR $\gamma$ staining was very similar to that observed for RAR $\beta$, as it was predominant in the cytoplasm of epithelial cells in both the NT and T tissues (Fig. 4). As with the other RARs, the majority of patients expressed RAR $\gamma$ in the NT tissues (50-75\% of cells), similar to the normal control group (data not shown). In the T tissues, only 1 (1.25\%) (stage II) showed no expression, 10 (12.5\%) showed weak expression, 19 (23.75\%) showed moderate expression and most $(50 ; 62.5 \%)$ showed strong RAR $\gamma$ expression. RAR $\gamma$ expression tended to differ at each CRC stage when assessed by ANOVA ( $\mathrm{P}=0.052)$ (Fig. 5). However, this value was probably attributable to the small number of patients in stage I (only 6 patients).

Correlation with patient outcome. $\mathrm{RAR} \alpha$ expression in the $\mathrm{T}$ tissues was positively correlated with CRC stage [correlation coefficient $(\mathrm{r})=0.0011$ ] and remission $(\mathrm{r}=0.027)$. However, it was negatively correlated with disease evolution $(\mathrm{r}=0.012)$, chemoresistance $(\mathrm{r}=0.024)$ and death $(\mathrm{r}=0.0047)$. RAR $\beta$ expression may be considered a marker of CRC development, as it decreased in conjuction with disease progression (confirmed by ANOVA at the two evaluations). Moreover, strong RAR $\beta$ expression in the $\mathrm{T}$ tissues was associated with a more favorable survival probability $(\mathrm{P}=0.0072$ at the first and $\mathrm{P}=0.1$ at the second evaluation) (Fig. $6 \mathrm{~A}$ and $\mathrm{B}$ ).

RAR $\beta$ expression in the NT tissues may serve as a marker of a more favorable prognosis, as its expression was positively 
associated with remission $(\mathrm{r}=0.021)$ and negatively associated with disease evolution $(r=0.022)$, chemoresistance $(r=0.016)$ and death $(\mathrm{r}=0.033)$. Although RAR $\beta$ was also expressed in the NT tissues of the patients as the internal control group, its high expression was linked to a longer survival $(\mathrm{P}=0.04)$ (Fig. 7).

RAR $\gamma$ expression in the NT tissues was negatively associated with disease evolution $(r=0.033)$. Moreover, its expression in the $\mathrm{T}$ tissues was negatively associated with chemoresistance $(r=0.014)$. Based on these results, RAR $\gamma$ may be used as an indicator of a more favorable prognosis for $\mathrm{CRC}$, although no significant association with survival probability was found $(\mathrm{P}>0.05)$.

\section{Discussion}

In the present study, the expression of the proliferation marker $\mathrm{Ki}-67$ and the three RARs in different stages of CRC, including the rare analysis of stage I (which is rarely operated on), was analyzed by immunohistochemistry in both the T and NT areas (the latter representing the tumor environment) of each patient.

Ki-67 immunoreactivity was present in the NT and $\mathrm{T}$ tissues of all of the patients analyzed, but no correlation with tumor grade or other parameters was established. Strong $\mathrm{Ki}-67$ reactivity was found in the $\mathrm{T}$ tissues, which confirmed the high proliferative activity of CRC, but the proliferation rate was not an indicator of disease progression, as observed for prostate cancer (28).

$\operatorname{RAR} \beta$ expression is commonly lost in various tumor types (12-20). In this study, RAR $\beta$ expression in the T tissues was not an indicator of tumor progression. Different RAR $\beta$ isoforms, with varying biological functions, have been identified. Two known RAR $\beta$ promoters and alternative splicing give rise to three major isoforms in humans $\left(\beta_{1}, \beta_{2}\right.$ and $\left.\beta_{4}\right)$. RAR $\beta_{2}$ is the most abundant, and the term $\operatorname{RAR} \beta$ used in the literature frequently refers to this isoform. The loss of $\operatorname{RAR} \beta_{2}$ expression during cancer development is associated with tumorigenesis and retinoid resistance. The induction of its expression suppresses carcinogenesis. RAR $\beta_{4}$ expression is also increased in various types of cancer, but induction of its expression increases the growth of tumor cells that do not express $\operatorname{RAR} \beta_{2}$ (29). In the present study, expression of RAR $\beta$ was examined without distinguishing its different isoforms, which explains our results. Evaluating the specific expression of the various RAR $\beta$ isoforms in different CRC stages and in pre-cancerous stages is of interest. RAR $\beta$ expression in the NT tissues was the most significant finding of the study, as it was correlated with remission. Therefore, as a positive marker, RAR $\beta$ may be an indicator of patient response to treatment and a prognostic marker of a beneficial clinical outcome.

RAR $\alpha$ expression in the $\mathrm{T}$ tissues was lower than that in the NT tissues and decreased from the early to late CRC stages (first follow-up, $\mathrm{P}=0.016$; second follow-up, $\mathrm{P}=0.0018$ ), as has been shown in head and neck tumors (13), carcinogenesis of the endometrium (12) and breast tumors (30). Its expression was also positively associated with remission, which reinforces the hypothesis that RAR $\alpha$ is a marker of disease progression.

Finally, RAR $\gamma$ expression in the $\mathrm{T}$ tissues decreased progressively with tumor stage $(\mathrm{P}=0.052)$, which suggests that RAR $\gamma$ may serve as an indicator of CRC tumor progression, as previously found in the carcinogenesis of the endometrium (12) and oral lesions (21). Its expression in the $\mathrm{T}$ tissues was also negatively correlated with chemoresistance. Therefore, weak RAR $\gamma$ expression or its loss in $\mathrm{T}$ tissues may be an indicator of a poor clinical outcome. In parallel, its expression was negatively correlated with disease progression in the NT tissues. Collectively, these results suggest that RAR $\gamma$ may be as a suitable indicator of treatment response for CRC.

Altered RAR expression is associated with the tumorigenic transformation of cells. Retinoids are potentially important due to their multi-target actions, and promising results have been obtained in different in vitro studies demonstrating the inhibition of cell growth, increased cell differentiation and the induction of apoptosis (3). Although in vitro growth inhibition of human CRC cells by retinoids or their analogues has been documented (31-33), prompting initial enthusiasm, the findings concerning their therapeutic efficacy in vivo remain controversial. Conflicting results have emerged, and retinoid resistance has been reported (34). The adverse effects of retinoids are also considerable; therefore, they must be used with caution. Further studies are warranted to clarify the mechanisms of retinoids and to improve their clinical usefulness, in particular in CRC.

In this patient cohort comprising 80 patients living in the Limousin region of France, Ki-67 and RAR expression was evaluated in tissues from patients with different stages of CRC by immunohistochemical analysis. The relationships found provide information complementary to the pTNM international classification. The mechanisms implied by the changes in RAR expression are not currently well defined. Further investigations are required to better understand the roles of retinoids in CRC carcinogenesis, in particular the corroboration of these results by a study on RXR expression. It may be useful to examine RAR expression in pre-cancerous patient tissues in order to improve patient care and the treatment of CRC, the second most common cause of death by cancer in industrialized countries.

\section{Acknowledgements}

This study was supported in part by the University of Limoges, La Ligue Contre le Cancer and the Région Limousin (to A.P.). H.A. is the recipient of a grant from the Conseil Régional du Limousin. We express our gratitude to Professor Descottes (deceased), Professor Valleix and Professor Gainant (Heads of the Departments of Surgery), to the technical experts of the Pathology Department, Limoges Teaching Hospital, for the helpful assistance with the immunohistochemistry, to 'La Tumorothèque du Limousin' for providing the samples and to Dr J. Cook-Moreau for the editorial assistance.

\section{References}

1. Wolbach B and Howe PR: Tissue changes following deprivation of fat soluble A vitamin. J Exp Med 42: 753-777, 1925.

2. De Luca LM: Retinoids and their receptors in differentiation, embryogenesis, and neoplasia. FASEB J 5: 2924-2933, 1991.

3. Altucci $\mathrm{L}$ and Gronemeyer $\mathrm{H}$ : The promise of retinoids to fight against cancer. Nat Rev Cancer 1: 181-193, 2001.

4. Mongan NP and Gudas LJ: Diverse actions of retinoid receptors in cancer prevention and treatment. Differentiation 75: 853-870, 2007.

5. Asou N: All-trans retinoic acid in the treatment of acute promyelocytic leukemia. Intern Med 46: 91-93, 2007.

6. Degos L and Wang ZY: All trans retinoic acid in acute promyelocytic leukemia. Oncogene 20: 7140-7145, 2001. 
7. Nagy L, Thomazy VA, Shipley GL, et al: Activation of retinoid $\mathrm{X}$ receptors induces apoptosis in HL-60 cell lines. Mol Cell Biol 15: 3540-3551, 1995

8. Germain P, Staels B, Dacquet C, Spedding M and Laudet V: Overview of nomenclature of nuclear receptors. Pharmacol Rev 58: 685-704, 2006

9. Germain P, Chambon P, Eichele G, et al: International Union of Pharmacology. LX. Retinoic acid receptors. Pharmacol Rev 58: 712-725, 2006.

10. Germain P, Chambon P, Eichele G, et al: International Union of Pharmacology. LXIII. Retinoid X receptors. Pharmacol Rev 58 760-772, 2006

11. Sun SY: Retinoic acid receptor beta and colon cancer. Cancer Biol Ther 3: 87-88, 2004.

12. Li R, Saito T, Tanaka R, et al: Hypermethylation in promoter region of retinoic acid receptor-beta gene and immunohistochemical findings on retinoic acid receptors in carcinogenesis of endometrium. Cancer Lett 219: 33-40, 2005.

13. Xu XC, Ro JY, Lee JS, Shin DM, Hong WK and Lotan R: Differential expression of nuclear retinoid receptors in normal, premalignant, and malignant head and neck tissues. Cancer Res 54: 3580-3587, 1994.

14. Kamradt $\mathbf{J}$ and Reichrath J: Expression of retinoic acid receptor proteins in basal cell carcinomas: an immunohistochemical analysis. J Histochem Cytochem 44: 1415-1420, 1996.

15. Widschwendter M, Berger J, Daxenbichler G, et al: Loss of retinoic acid receptor beta expression in breast cancer and morphologically normal adjacent tissue but not in the normal breast tissue distant from the cancer. Cancer Res 57: 4158-4161, 1997.

16. Picard E, Seguin C, Monhoven N, et al: Expression of retinoid receptor genes and proteins in non-small-cell lung cancer. J Nat Cancer Inst 91: 1059-1066, 1999.

17. Zhang W, Rashid A, Wu H and Xu XC: Differential expression of retinoic acid receptors and p53 protein in normal, premalignant, and malignant esophageal tissues. J Cancer Res Clin Oncol 127: 237-242, 2001.

18. Richter F, Joyce A, Fromowitz F, et al: Immunohistochemical localization of the retinoic acid receptors in human prostate. J Androl 23: 830-838, 2002.

19. Haugen BR, Larson LL, Pugazhenthi U, et al: Retinoic acid and retinoid $X$ receptors are differentially expressed in thyroid cancer and thyroid carcinoma cell lines and predict response to treatment with retinoids. J Clin Endocrinol Metab 89: 272-280, 2004.

20. Karamouzis MV, Sotiropoulou-Bonikou G, Vandoros G, Varakis I and Papavassiliou AG: Differential expression of retinoic acid receptor beta $(\mathrm{RAR} \beta)$ and the AP-1 transcription factor in normal, premalignant and malignant human laryngeal tissues. Eur J Cancer 40: 761-773, 2004.

21. Ralhan R, Chakravarti N, Kaur J, et al: Clinical significance of altered expression of retinoid receptors in oral precancerous and cancerous lesions: Relationship with cell cycle regulators. Int J Cancer 118: 1077-1089, 2006.
22. Alvarez S, Germain P, Alvarez R, Rodriguez-Barrios F, Gronemeyer $\mathrm{H}$ and de Lera AR: Structure, function and modulation of retinoic acid receptor beta, a tumor suppressor. Int J Biochem Cell Biol 39: 1406-1415, 2007.

23. Bossard N, Veltenc M, Remonteta L, et al: Survival of cancer patients in France: A population-based study from The Association of the French Cancer Registries (FRANCIM). Eur J Cancer 43: 149-160, 2007.

24. Greene FL, Page DL, Fleming I, et al: AJCC (American Joint Committee on Cancer) Cancer Staging Manual. 6th edition. Springer-Verlag, New York, p113, 2002.

25. Gerdes J, Lemke H, Baisch H, Wacker HH, Schwab U and Stein H: Cell cycle analysis of a cell proliferation-associated human nuclear antigen defined by the monoclonal antibody Ki-67. J Immunol 133: 1710-1715, 1984

26. Du L, Wang $\mathrm{H}, \mathrm{He} \mathrm{L}$, et al: CD44 is of functional importance for colorectal cancer stem cells. Clin Cancer Res 14: 6751-6760, 2008.

27. Hammer $\varnothing$, Harper DAT and Ryan PD: PAST: Paleontological statistics software package for education and data analysis. Palaeontologia Electronica 4: 9, 2001.

28. Gyftopoulos K, Perimenis P, Sotiropoulou-Bonikou G, Sakellaropoulos G, Varakis I and Barbalias GA: Immunohistochemical detection of retinoic acid receptor-alpha in prostate carcinoma: correlation with proliferative activity and tumor grade. Int Urol Nephrol 32: 263-269, 2000.

29. Xu XC: Tumor-suppressive activity of retinoic acid receptor-beta in cancer. Cancer Lett 253: 14-24, 2007.

30. Van der Leede BM, Geertzema J, Vroom TM, et al: Immunohistochemical analysis of retinoic acid receptor-alpha in human breast tumors: retinoic acid receptor-alpha expression correlates with proliferative activity. Am J Pathol 148: 1905-1914, 1996.

31. Lee MO, Han SY, Jiang S, Park JH and Kim SJ: Differential effects of retinoic acid on growth and apoptosis in human colon cancer cell lines associated with the induction of retinoic acid receptor beta. Biochem Pharmacol 59: 485-496, 2000.

32. Nicke B, Kaiser A, Wiedenmann B, Riecken EO and Rosewicz S: Retinoic acid receptor alpha mediates growth inhibition by retinoids in human colon carcinoma HT29 cells. Biochem Biophys Res Commun 261: 572-577, 1999.

33. Kim EJ, Kang YH, Schaffer BS, Bach LA, MacDonald RG and Park JH: Inhibition of Caco-2 cell proliferation by all-trans retinoic acid: role of insulin-like growth factor binding protein-6. J Cell Physiol 190: 92-100, 2002.

34. Freemantle SJ, Spinella MJ and Dmitrovsky E: Retinoids in cancer therapy and chemoprevention: promise meets resistance. Oncogene 22: 7305-7315, 2003. 